\title{
TOWARDS TECHNOLOGY AND ENTREPRENEURSHIP: A PERSPECTIVE WITH CYCLIC CONDITIONS
}

\author{
Leon Pretorius ${ }^{1}$, Vida Davidavičiené⿱ ${ }^{2}$ \\ ${ }^{I}$ Graduate School of Technology Management, University of Pretoria, \\ Lynwood road, Pretoria 0028, South Africa \\ ${ }^{2}$ Department of Business Technologies and Enterpreneurship, Vilnius Gediminas Technical \\ University, Sauletekio al 11, Vilnius, Lithuania \\ E-mails: ${ }^{1}$ leon.pretorius@up.ac.za; ${ }^{2}$ vida.davidaviciene@vgtu.lt (corresponding author)
}

\begin{abstract}
In this paper aspects of technology and entrepreneurship interaction are considered. Firstly some dynamic aspects of technology are presented from a brief literature perspective. This is then contrasted to and integrated with some elements of entrepreneurship where cyclic aspects are influenced by unemployment in the business and possibly technology environment. This work is built on some views presented by previous authors such as Faria and others. Their work is extended to a conceptual systems thinking model representing cyclic factors in entrepreneurship using a causal loop diagram (CLD) approach. Some business statistics from databases are gathered and analysed for entrepreneurship to show and support some arguments of Faria and others about cyclic nature of entrepreneurship. A conceptual system dynamics approach for the entrepreneurship dynamics is presented based on previous research.
\end{abstract}

Keywords: simulation, systems management, technology system, system dynamics, cyclic, business competition.

Jel Classification: M15, O32, O33, C6.

\section{Introduction}

Development of technologies makes impact to all sectors of economic, social and other activities. Recently, a lot of attention was focused on entrepreneurship in the context of high technologies implementation and development. This paper carries forward some of the research perspectives on technology dynamics presented previously by L. Pretorius and J. H. C. Pretorius (2014). This work focused on the aspects of simulation of technologies that interact whilst exposed to competitive business environments. Some future research suggested was to explore further the work of Faria and Cuestas (2008) on entrepreneurship and unemployment. Their work as well as ensuing work (Faria, Cuestas, \& Mourelle, 2008) was focused on suggesting some dynamic and cyclic characteristics of entrepreneurship and linking their theoretical approach to some econometric analyses.

The current research in this paper is aimed at addressing some of the dynamics of entrepreneurship suggested by Faria and others using a systems thinking and to some extent a system dynamics approach. The difference in this paper is that the equations presented by Faria and others will be extended to some nonlinear domain as well. The conceptual causal loop mapping (CLD) for linking the dynamics of entrepreneurship and unemployment alluded to by Faria and others conceptually will also be deductively reasoned and some resulting simulation results are presented and discussed in the next sections.

The research objective addressed in this paper is thus focused on the cyclic dynamic behaviour displayed by entrepreneurship in connection with unemployment. The research method followed is exploratory (Cooper \& Schindler, 2008) in nature and supplemented by a systems thinking (Frandberg, 2003; Jackson, 2003) and to some extent a system dynamics approach (Forrester, 1971, 1994, 1999) suited well for assessing and in some depth case studies in business and technology entrepreneurship.

\section{Theoretical background}

To explore more fundamentally some of the dynamic relationships the concept of entrepreneurship should be carefully evaluated. Since different scholars analyse different aspects of entrepreneur- 
ship, and different key factors affecting entrepreneurship itself in this article at least some definitions of entrepreneurship and possible relationship to technology transfer and economic aspects such as unemployment need some attention.

Hughes (2003) provide some views on technology, knowledge transfer and entrepreneurship. Specifically, he links technology-based firms and their entrepreneurship activities to the technology transfer process. Specific mention is also made of linking "proxies for entrepreneurship, such as small business shares, or self-employment, to cross national variations in growth or unemployment rates".

In this research paper the authors focus also on the dynamics of entrepreneurship and unemployment. As such one can perhaps then use related entrepreneurship indices from (OECD). Another entrepreneurship proxy used at times is the business share termed as the number of business owners as a proportion of the labour force or employment (Faria \& Cuestas, 2008) (OECD). Amoroso and Link (2018) examines the role of innovation and gender ownership as determinants of employment growth in Europe. European specifics were analysed by Davidavičienè and Lolat (2016), Jankelová, Jankurová, Beňová, and Skorková (2018), Tvaronavičiené (2016), Roman, Bilan, and Ciumaș (2018) and Teixeira, Casteleiro, Rodrigues, and Guerra (2018) as well.

Self-employment, business creation and innovation are also essential characteristics of entrepreneurship especially in an urban context as indicated in the work of Faggio and Silva (2014). Platzek, Pretorius, and Winzker also specifically refer to the concepts of innovation, change, new business and the bigger picture in their discussion of the entrepreneurial mindset. The extent of institutional openness in universities towards university-industry collaboration relation and effect of generation of knowledge-intensive spin-offs and academic patenting activity in the context of development countries were demonstrated by Fischer, Schaeffer, Vonortas, and Queiroz (2018).

With the bigger picture or the bigger system in mind some researchers specifically refer to the extent that geographical location seems to affect entrepreneurship. The relationships between the entrepreneurship, cultural values, and GDP per capita in developed countries were presented by Fernández-Serrano, Berbegal, Velasco, and Expósito (2018). Factors of productivity fostered by entrepreneurship and its impact on national level economic efficiency were analysed by $\mathrm{Du}$ and
O'Connor (2018). Geographical location seems to affect entrepreneurship e.g. (Fernhaber, Gilbert, \& McDougall, 2008; Mitchneck, 2017). Developing countries entrepreneurship specifics were analysed widely and in quite different approaches by researchers as well (Dana \& Ratten 2017; Jodoin 2017; Muhammad, Waren, \& BinteSaleem, 2017; Bastian, Sidani, \& El Amine, 2018; Bongomin, Munene, Ntayi, \& Malinga, 2018; Yessoufou, Blok, \& Omta, 2018). Some effects of geographical location are also alluded to in the results and validation sections of this paper where entrepreneurship indices for different countries are mentioned and differences in entrepreneurship dynamics are indicated from secondary data analysis.

It thus seems to be appropriate to use elements of new business creation as proxy for entrepreneurship. There are many definitions to be found for entrepreneurship in the literature (Lazear, 2005; Klein, 2008; Platzek et al., 2014). For the purpose of this paper the focus in entrepreneurship will be on technology, innovation, market, strategic, new business employment creation and system issues related to the entrepreneurial mindset. The entrepreneurial mindset is also explored by Van der Lingen and van Niekerk (2015) in their assessment of enterprising tendency of Science Engineering and Technology learners. The systems thinking method or approach for example promoted by Jackson (2003) and Meadows and Wright (2008) is used to some extent in the development of the unemployment and entrepreneurship systems model in the next section.

System dynamics (Forrester, 1971, 1994, 1999; Sterman, 2000), systems thinking (Meadows \& Wright, 2008) as well as computer simulation implementation in Vensim Anon (2018) are integrated in the research approach used and illustrated in the next sections. Some qualitative validation of the system dynamics model for entrepreneurship as suggested by Barlas (1996) is also provided by using and analysing economic data obtained from OECD .

In summary the research method used in this paper is focused on addressing the following basic research questions: Is there a dynamic relationship of cyclic nature between unemployment and entrepreneurship? Can this relationship if it exists be implemented and simulated using a system dynamics approach? The next section will focus on the background and development of a systems model for entrepreneurship and unemployment. 


\section{The unemployment and entrepreneurship systems model}

The systems model describing the interaction between entrepreneurship and unemployment presented in this paper is based on the economic explanation and basic equations presented by Faria (Faria \& Cuestas, 2008). Their economic explanation for the feedback relationships between unemployment and entrepreneurship is summarised as follows.

An increase in unemployment leads to creation of new businesses. The work of Dohse and Vaona (2018) also presents some evidence for this statement. This in turn results in more employment opportunities (also in some sense supported by Alonso-Borrego and Collado (2002) when they refer to a positive relationship between innovation and employment) leading to a decrease in unemployment. Furthermore an increase in new businesses can lead to more competition (an idea for example also supported by Porter (1985) in his discussion on technological change and competition) resulting in the closing of businesses that are not as competitive. This will in the end lead to increase in unemployment again.

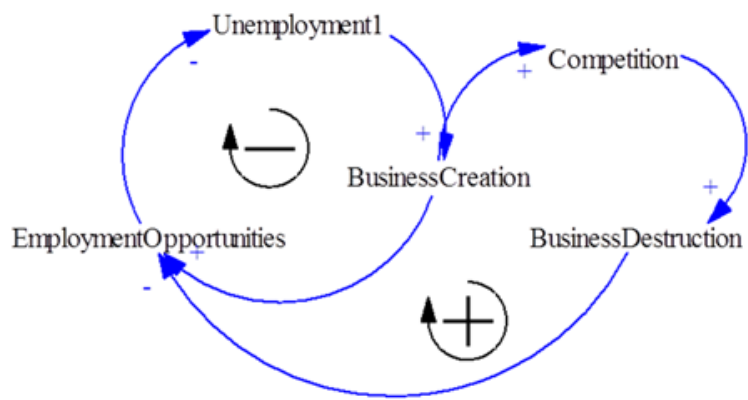

Figure 1. Unemployment and Entrepreneurship Causal loop diagram (source: created by authors)

This is essentially a form of systems thinking (Jackson, 2003) that can be represented in the causal loop diagram developed for this paper using software Vensim (Eberlein \& Peterson, 1992; Barlas, 1996; Eberlein, 2010; Anon, 2018). The CLD in Figure 1 also represents in some initial form the dynamic hypothesis associated with the entrepreneurship model which will be extended to a system dynamic model further in this section. In Figure 1. Business creation is intended to be a proxy for entrepreneurship as described in section 1 and also supported by Faria and Cuestas (2008).

This systems thinking CLD was not provided by Faria and Cuestas (2008) and is presented here as some extended discussion of their work. This CLD provides the basis for the development of the following unemployment and entrepreneurship system dynamics (SD) model. The systems thinking model for entrepreneurship is represented in the CLD with two interlinked causal loops one being a reinforcing $(+)$ cycle and the other a balancing $(-)$ cycle. This however on its own does not necessarily indicate cyclic dynamic behaviour for entrepreneurship.

To model this detailed behaviour a systems dynamic model for entrepreneurship together with the appropriate modeling equations is required. The software Vensim is again used for this system dynamics model development in this paper. In its most basic understanding Vensim is a simulator for solving and simulating systems of differential equations. In these equations rates are the time differentiated form of model equations and are typically represented by valves in the Vensim system dynamics models. Furthermore the resulting integrated forms of these rate equations are then represented by boxes or levels in the Vensim diagrams.

For this research the two basic rate differential equations for unemployment $(\mathrm{U})$ and entrepreneurship (E) presented by Faria and Cuestas (2008) are adapted for use in the system dynamics Vensim model for unemployment and entrepreneurship. For the current purpose the system dynamics model boundaries are drawn around the concepts of entrepreneurship and unemployment.

Other factors such as social structure, for example across national or geographical boundaries, are not directly accounted for or can be lumped in the exogenous factors such as E1 etc. See for example (Faria et al., 2008; Faria \& Cuestas, 2008). The basic equations adapted from Faria and Cuestas (2008) represent for example the positive relation between unemployment level and rate of business creation or entrepreneurship moderated negatively by the competition between new businesses in equation (2):

$$
\begin{aligned}
& \dot{U}=U 1-E ; \\
& \dot{E}=U-E \times E 1+F 1 .
\end{aligned}
$$

Where $U 1, E 1$ and $F 1$ are exogenous model variables related to steady state unemployment level, time delays and steady entrepreneurship parameters respectively.

When these equations are implemented in Vensim the unemployment entrepreneurship system dynamics model in Figure 2 results with for example the box level Entrepreneurship having an integral equation (3) and initial value 1 associated with it: 
Entrepreneurship $=$

INTEG (EntrepreneurshipChangeRate,1).

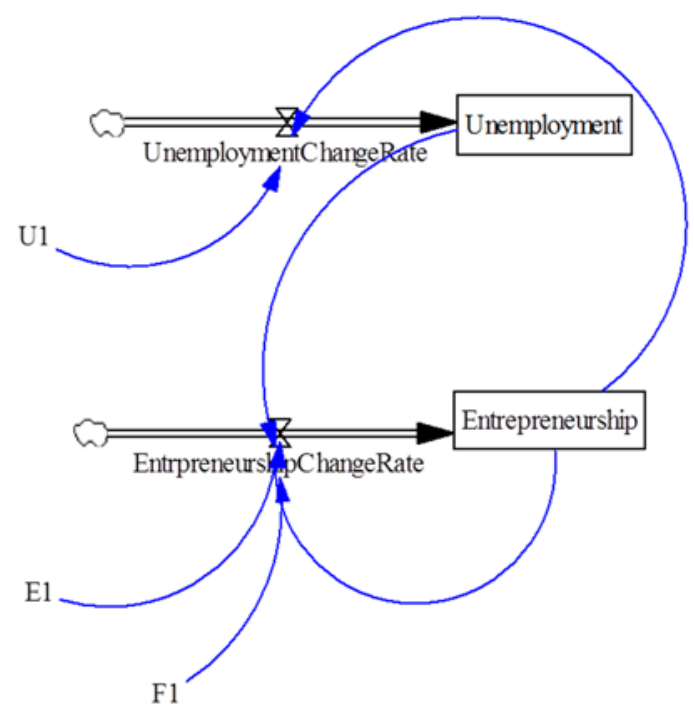

Figure 2. Unemployment and Entrepreneurship System Dynamics (SD) model (source: created by authors)

The base case SD model has been implemented using the model parameter value shown in Table 1. Initial values of 25 and 11 percent are used for Unemployment U and Entrepreneurship $E$ to be representative to some extent of typical economic values obtained for certain countries in Europe and Africa.

Table 1. Some typical base case model parameters (source: created by authors)

\begin{tabular}{|l|c|c|c|c|c|}
\hline & \multicolumn{5}{|c|}{ andel parameters- equations (1) } \\
\hline $\begin{array}{l}\text { Units: Percent- } \\
\text { age or Dmnl }\end{array}$ & U1 & E1 & F1 & $\begin{array}{c}\text { U } \\
\text { ini- } \\
\text { tial }\end{array}$ & $\begin{array}{c}\text { E } \\
\text { ini- } \\
\text { tial }\end{array}$ \\
\hline $\begin{array}{l}\text { Base case } \\
\text { values }\end{array}$ & 20 & 0.5 & 0 & 25 & 11 \\
\hline
\end{tabular}

\section{Some results and discussion for cyclic entrepreneurship behaviour.}

In this section firstly some system dynamics (SD) simulation results obtained with the basic entrepreneurship unemployment SD model developed in Vensim and presented in the previous section are discussed. The Euler integration method is used in Vensim with numerical time integration increment of 0.0625 year for all simulation results presented in the next section. Simulated results are presented generally for a period of 10 years for all cases. For qualitative comparison with some OECD economic data later on in this section a base case simulation has been done using the model parameter values indicated in table 1 .

The latter part of this section is devoted to some qualitative validation of the Entrepreneurship SD model. For this the qualitative SD dynamic hypothesis validation approach suggested by Barlas (1996) is followed. The validation is here focused mainly on substantiating some dynamic patterns such as trends, frequencies, periods etc. observed from data gathered and analysed using OECD . The entrepreneurship real data analysed was focused mainly on the cases such as Spain, Ireland, Lithuania and South to compare dynamic trends where relevant between cases and SD simulation data.

Initial system dynamic simulation results for the base case with initial values of $25 \%$ and $11 \%$ for Unemployment and Entrepreneurship respectively are shown in Figure 3. For this entrepreneurship simulation results a time period of cyclic behaviour of approximately 6.5 years is indicated.

What is also evident from the simulation results is that both Entrepreneurship en Unemployment show dampened cyclic behaviour over time. A maximum of approximately $27.4 \%$ for Unemployment at time 0.5 year and $32.5 \%$ Entrepreneurship at year 1.75 is simulated for this base case. This simulated dampened behaviour is a result of the reduction in business creation that may come from the competition created be entrepreneurship as also indicated by J. R. Faria and Cuestas (2008).

To investigate what the effect of a policy change of restricting competition from entrepreneurial efforts would be some nonlinearity was introduced on the parameter E1 such that E1 would on its own be dependent on Entrepreneurship (E) as indicated in Figure 4. Such a policy change could be the result of a firm acquiring a nearby technology competitor and thus reducing the competition from that source on itself. This is for example also illustrated by Grimpe and Hussinger (2008) in their work on competition and competitive behaviour in technology markets. This focus of policy as a course of action related to a change in system structure and or decision rules is also emphasised by authors such as Sterman (2000), Saeed (2014) and others.

The simulation results for such a nonlinear policy change related to Entrepreneurship are shown in Figure 5. A simulated increase in Entrepreneurship from $32.9 \%$ to $35.8 \%$ at year 1.75 is indicated for the change from the base case to the 
nonlinear case. This increase may then be ascribed to the relaxation of the nonlinear competition effect of entrepreneurship in the adapted SD model.

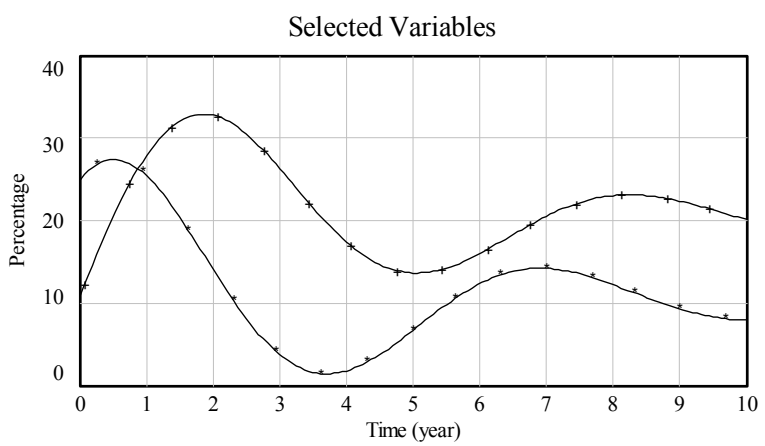

Entrepreneurship : CurrentEntrep20P + + + + + + + + + + Unemployment : CurrentEntrep20P

Figure 3. Entrepreneurship and Unemployment simulated using the SD model and basic parameter set (source: created by authors)

\section{Effect of Entrepreneurship on E1}

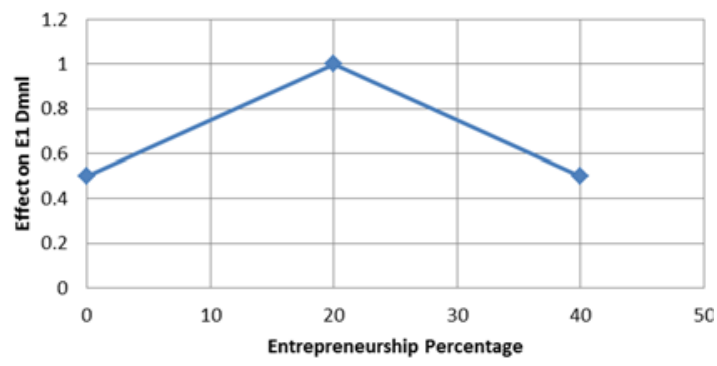

Figure 4. Some nonlinear effect of Entrepreneurship on E1 (source: created by authors)

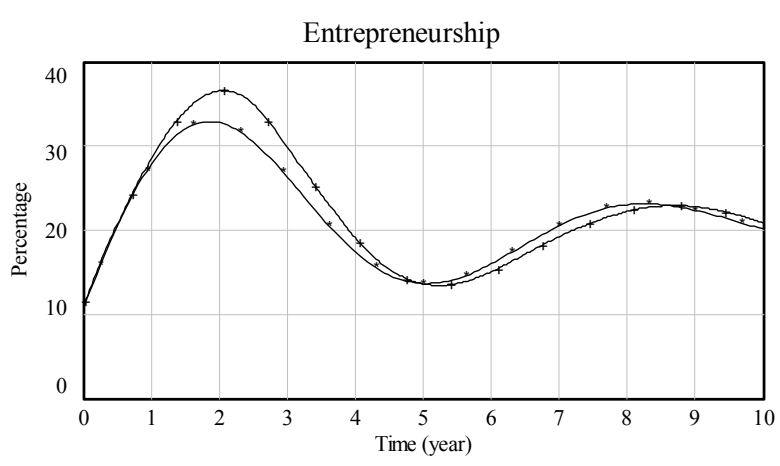

Entrepreneurship : CurrentEntrep20PaNon30

Entrepreneurship : CurrentEntrep20P

Figure 5. Entrepreneurship simulation with nonlinear effect of Entrepreneurship on E1

(source: created by authors)

This concludes the very exploratory initial simulation research shown using the Entrepreneurship SD model. Suffice it to say at this stage that the indicated cyclic behaviour of Entrepreneurship and Unemployment can be shown to be strongly dependent on the internal structure of the system parameters. As such some of the real word findings from OECD data can show totally damped and even exponential type growth behaviour under certain conditions. The rest of this section is now devoted to some qualitative validation (Barlas, 1996) of initial SD model results for Entrepreneurship and Unemployment. Specifically aspects of four cases were analysed from OECD data namely that of Spain, Ireland, Lithuania and South Africa.

The OECD business indicators for entrepreneurship and unemployment as defined in that source were analysed for specific periods of time and used for qualitative comparison to SD simulations provided previously. Specifically new enterprise births as a percentage value were used as proxy for entrepreneurship in this exploratory research. Also availability of OECD data in this format led the authors as a first comparison to use this proxy and not the businesses created per labour force proxy suggested by Faria and Cuestas (2008) at this stage.

Results of analyses of OECD data for the 4 cases considered in this paper are shown in Figure 6 to Figure 10. From these figures it is qualitatively concluded that all 4 cases, Spain, Ireland, Lithuania and South Africa, seem to shown practical evidence of cyclic behavior in Enterprise Births (here considered as proxy for Entrepreneurship) and or Unemployment to various degrees.

Spain and Ireland New Enterprise Births \%

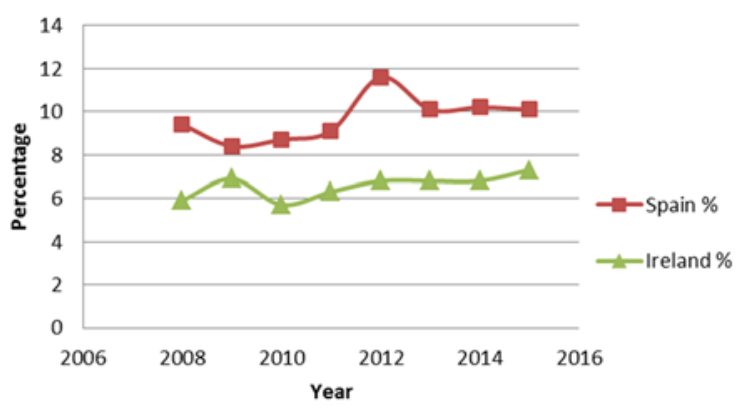

Figure 6. New enterprise births as proxy for Entrepreneurship; Spain and Ireland data analysed from OECD (source: created by authors)

Figure 6. shows for example periodic behavior in Entrepreneurship for Spain and Ireland with time period ranging between 6 and 7 years. Figure 7 shows a similar trend for Lithuania with period approximately 7 years. This is also supported by the periodic behaviour of Unemployment for Spain with period of approximately 10 years between the years 2005 and 2015 inferred from Figure 9. These values for periodic behavior are also 
supported in the SD simulation results presented previously as well as the data from Faria and Cuestas (2008).

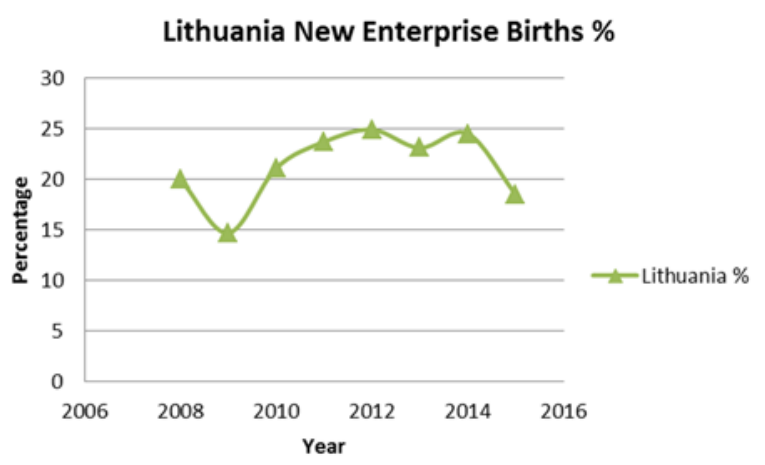

Figure 7. New enterprise births as proxy for Entrepreneurship; Lithuania data analysed from OECD (source: created by authors)

The Entrepreneurship Index on a scale of 15 for year 2013 with data analysed for a number of global countries from OECD is shown in Figure 8 . From these results it may be inferred that there are distinct differences in entrepreneurial action in different countries or regions. This means that geographical location seems to matter where entrepreneurship is concerned as also mentioned by Fernhaber et al. (2008). In this respect it is worth mentioning the differences in Entrepreneurship Index in 2013 for Lithuania (4.43), Ireland (4.02), Spain (3.9) and South Africa (3.83).

If one compares the analysed new enterprise birth rates from Figure 6 and Figure 7. Lithuania features higher than both Spain and Ireland across the entire time span from 2008 to 2015. This again supports the result for geographical effect on entrepreneurship gleaned from Figure 8. There seems to be an anomaly between Figure 8 and Figure 6 for the year 2013.

The results from Figure 6 seem to indicate that the enterprise births as proxy for entrepreneurship for Ireland was below that of Spain for the entire period. In Figure 8 the Entrepreneurship Index for Spain was however below that of Ireland. One should however remember that in reality entrepreneurship is influenced by many more factors than only enterprise births. These may include factors such as self-employment, culture, bankruptcies etc. as shown also in OECD .

For the purpose of initial exploratory research on the dynamic effects between entrepreneurship and unemployment in this paper a choice was made to have enterprise births as a proxy for entrepreneurship. Although this seems to be reasonable choice especially just to explore the possibility of cyclic behaviour in entrepreneurship as successfully shown in the results of for example Figure 3. One has to be careful in evaluating all the results as shown here.

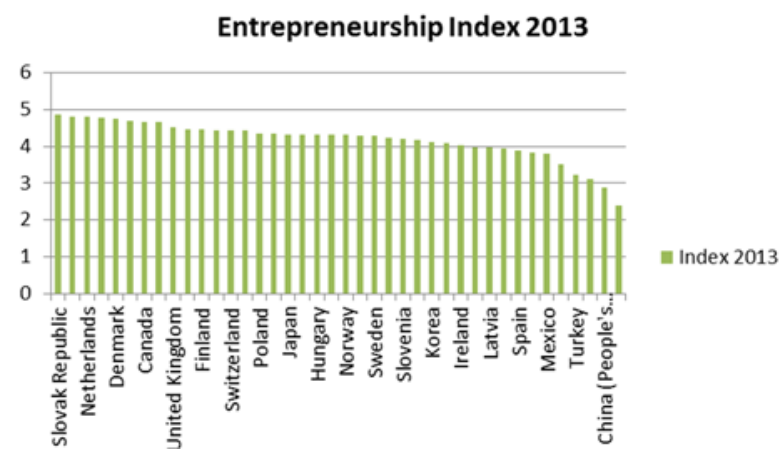

Figure 8. Entrepreneurship Index; data analysed from OECD (source: created by authors)

Some practical economic indicator evidence for periodic behavior with damping or competition effect of Unemployment for Spain is also presented for the time span from 1999 to 2007 in Figure 9. This trend of Unemployment is qualitatively similar to the SD simulation results presented in Figure 3 and Figure 5. If one qualitatively compares Figure 6 and Figure 9 the trend of data analysed for the period after 2010 seems to indicate that as enterprise births increase unemployment decreases with a time delay to some extent at least for Spain. This supports the dynamic hypotheses upon which the system dynamics model for entrepreneurship was developed in the previous section.

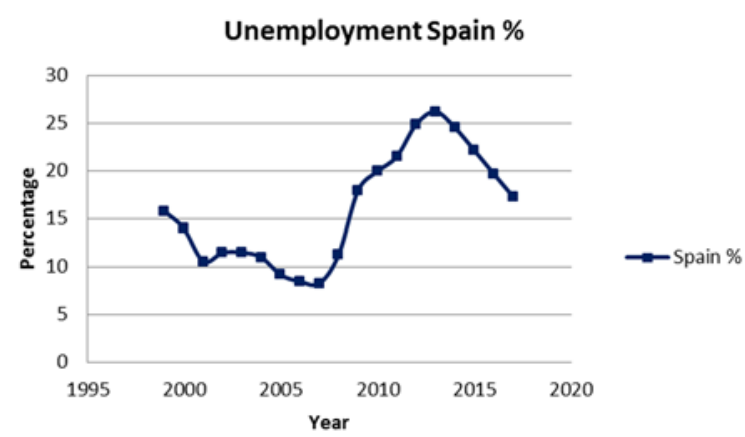

Figure 9. Unemployment rate; Spain data analysed from OECD (source: created by authors)

In Figure 10 one can again observe the general cyclic dynamic trend in unemployment rate for South Africa analysed from OECD data between the year 2000 and 2010. The general trend that is observed implies a cyclic period of approximately 10 years for unemployment that seems to at least qualitatively support the SD simulation results presented previously. From the year 2010 to 2016 however a general increasing trend is seen. 
This may support a previous statement in the SD model development section that the behaviour of the SD model is generally determined by the model structure and not necessarily external conditions. It can be shown in principle that the SD model may deliver exponential type results for a particular choice of model parameters related to the model structure.

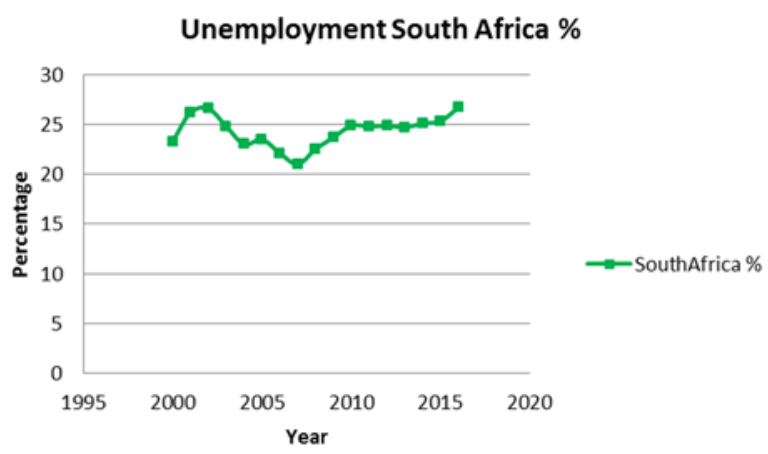

Figure 10. Unemployment rate; South Africa data analysed from OECD (source: created by authors)

The next section will address some conclusions from the current research results obtained for entrepreneurship and unemployment. Specific reference is made to the initial research questions posed in the introduction to the paper.

\section{Conclusions}

The brief literature review presented in the introduction section provided some relevant conclusions. The research of Faria and Cuestas (2008) was identified as a possible source for basic modeling of entrepreneurship in connection with unemployment. This work was extended in this paper using a systems thinking approach to establish a causal loop model for the creation of business and thus entrepreneurship integrated with unemployment. This did not form part of the original work of Faria. Furthermore a system dynamics model was created in this paper that can be used as a business decision making tool to address policy issues with entrepreneurship for example related to mergers and acquisitions in technology markets.

This then lead to the conclusion related to the first research question about the existence or not of cyclic behaviour of entrepreneurship and unemployment in a (technology) business environment asp posed in the introduction section of this paper. Economic and Entrepreneurship data gathered and analysed from the OECD source for the cases of Spain, Ireland, Lithuania and South Africa generally addressed the research question positively.

This data analysis was also used to qualitatively validate the system dynamics model developed in this paper incorporating some of the theory of Faria and others for entrepreneurship and unemployment. This addressed the second research question of this paper about the possibility of establishing a system dynamics model for the entrepreneurship unemployment cyclic behaviour. In this SD simulation process it was also shown that the entrepreneurship dynamic behaviour is highly dependent on the structure and parameter values associated with the interacting entrepreneurship unemployment system. This SD simulation tool that was developed in this paper can now be usefully employed as a business decision making and policy testing tool taking note of the assumptions made such as the fact that for example culture of organisations was not directly taken into account in the SD model.

Future research resulting from this paper may include extending structure of the SD model to take the dynamic behaviour of technology development into account. This may for example include some research effort to link the technology interaction model presented by L. Pretorius and J. H. C. Pretorius (2014) with the current entrepreneurship and unemployment system model shown in this paper. Further practical business and technology cases representing dynamic entrepreneurship effects may also be identified and analysed for future research to serve as possible sources of business and technology SD model validation.

\section{Acknowledgements}

The research support of the University of Pretoria, the Vilnius Gediminas Technical University and the National Research Foundation (NRF) in South Africa is acknowledged.

\section{References}

Alonso-Borrego, C., \& Collado, D. (2002). Innovation and job creation and destruction. Recherches Economiques de Louvain, 68(1), 148-148. https://doi.org/10.3917/rel.681.0148

Amoroso, S., \& Link, A. N. (2018). Under the AEGIS of knowledge-intensive entrepreneurship: employment growth and gender of founders among European firms. Small Business Economics, 50(4), 899-915. https://doi.org/10.1007/s11187-017-9920-4

Anon. (2018). [Vensim 5 Modeling Guide].

Barlas, Y. (1996). Formal aspects of model validity and validation in system dynamics. System Dynamics Review, 
12(3), 183-210. https://doi.org/10.1002/(SICI)10991727(199623)12:3<183::AID-SDR103>3.0.CO;2-4

Bastian, B. L., Sidani, Y. M., \& El Amine, Y. (2018). Women entrepreneurship in the Middle East and North Africa. Gender in Management: An International Journal, 33(1), 14-29. https://doi.org/10.1108/GM-07-2016-0141

Bongomin, G. O. C., Munene, J. C., Ntayi, J. M., \& Malinga, C. A. (2018). Determinants of SMMEs growth in post-war communities in developing countries. World Journal of Entrepreneurship, Management and Sustainable Development, 14(1), 50-73. https://doi.org/10.1108/WJEMSD-06-2017-0026

Cooper, D. R., \& Schindler, P. S. (2008). Business research methods (10th ed.). Boston: McGraw-Hill Irwin.

Dana, L.-P., \& Ratten, V. (2017). International entrepreneurship in resource-rich landlocked African countries. Journal of International Entrepreneurship, 15(4), 416435. https://doi.org/10.1007/s10843-017-0211-6

Davidavičienè, V., \& Lolat, I. (2016, May). Migrant entrepreneurship in Europe: challenges and opportunities. 9th International Scientific Conference of Business and Management (pp. 1-14). Vilnius, Lithuania. https://doi.org/10.3846/bm.2016.72

Dohse, D., \& Vaona, A. (2018). Unemployment and new business formation - new insights into a complex relationship. Applied Economics Letters, 25(8), 523-526. https://doi.org/10.1080/13504851.2017.1343437

Du, K., \& O'Connor, A. (2018). Entrepreneurship and advancing national level economic efficiency. Small Business Economics, 50(1), 91-111. https://doi.org/10.1007/s11187-017-9904-4

Eberlein, R. (2010). Getting started with Vensim. System Dynamics Society.

Eberlein, R. L., \& Peterson, D. W. (1992). Understanding models with Vensim ${ }^{\mathrm{TM}}$. European Journal of Operational Research, 59(1), 216-219.

https://doi.org/10.1016/0377-2217(92)90018-5

Faggio, G., \& Silva, O. (2014). Self-employment and entrepreneurship in urban and rural labour markets. Journal of Urban Economics, 84, 67-85. https://doi.org/10.1016/j.jue.2014.09.001

Faria, J., Cuestas, J., \& Mourelle, E. (2008). Entrepreneurship and unemployment: a nonlinear bidirectional causality?. Economic Modelling, 27(58), 1282-1291.

Faria, J. R., \& Cuestas, J. C. (2008). Unemployment and entrepreneurship: a cyclical relation?. Economics Letters, 105(3), 318-320 https://doi.org/10.1016/j.econlet.2009.09.004

Fernández-Serrano, J., Berbegal, V., Velasco, F., \& Expósito, A. (2018). Efficient entrepreneurial culture: a cross-country analysis of developed countries. International Entrepreneurship and Management Journal, 14(1), 105-127. https://doi.org/10.1007/s11365-017-0440-0

Fernhaber, S. A., Gilbert, B. A., \& McDougall, P. P. (2008). International entrepreneurship and geographic location: an empirical examination of new venture internationalization. Journal of International Business Studies, 39(2), 267-290. https://doi.org/10.1057/palgrave.jibs. 8400342

Fischer, B. B., Schaeffer, P. R., Vonortas, N. S., \& Queiroz, S. (2018). Quality comes first: university-industry collaboration as a source of academic entrepreneurship in a developing country. The Journal of Technology Transfer, 43(2), 263-284.

https://doi.org/10.1007/s10961-017-9568-x
Forrester, J. W. (1971). World dynamics, Wright. LN, Cambridge.

Forrester, J. W. (1994). System dynamics, systems thinking and soft OR. System Dynamics Review, 10(2-3), 245256. https://doi.org/10.1002/sdr.4260100211

Forrester, J. W. (1999). System dynamics: the foundation under systems thinking. Sloan School of Management, Massachusetts Institute of Technology, Cambridge, MA, 2139(1).

Frandberg, T. (2003). Systems thinking - a studie of alternatives of R. Flood, M. Jackson, W. Ulrich \& G. Midgley. International Journal of Computers, Systems and Signals, 4(1), 33-41.

Grimpe, C., \& Hussinger, K. (2008). Pre-empting technology competition through firm acquisitions. Economics Letters, 100(2), 189-191.

https://doi.org/10.1016/j.econlet.2008.01.003

Hughes, A. (2003). Knowledge transfer, entrepreneurship and economic growth: some reflections and implications for policy in the Netherlands. University of Cambridge. Retrieved from https://www.cbr.cam.ac.uk/ fileadmin/user_upload/centre-for-business-research/ downloads/working-papers/wp273.pdf

Yessoufou, A. W., Blok, V., \& Omta, S. W. F. (2018). The process of entrepreneurial action at the base of the pyramid in developing countries: a case of vegetable farmers in Benin. Entrepreneurship and Regional Development, 30(1-2), 1-28. https://doi.org/10.1080/08985626.2017.1364788

Jackson, M. C. (2003). Systems thinking: creative holism for managers. Wiley.

Jankelová, N., Jankurová, A., Beňová, M., \& Skorková, Z. (2018). Security of the business organizations as a result of the economic crisis. Entrepreneurship and Sustainability Issues, 5(3), 659-671. https://doi.org/10.9770/jesi.2018.5.3(18)

Jodoin, S. (2017). The transnational policy process for REDD+ and domestic policy entrepreneurship in developing countries. Environment and Planning C: Politics and Space, 35(8), 1418-1436. https://doi.org/10.1177/2399654417719287

Klein, P. G. (2008). Strategic entrepreneurship. Strategic Entrepreneurship Journal, 2(3), 175-190. https://doi.org/10.4135/9781452229805.n587

Lazear, E. P. (2005). Entrepreneurship. Journal of Labor Economics, 23(4), 649-680. https://doi.org/10.1086/491605

Meadows, D. H., \& Wright, D. (2008). Thinking in systems: a primer $(240$ p.). Chelsea Green Publishing.

Mitchneck, B. (2017). Geography matters: discerning the importance of local context. Slavic Review, 64(3), 491516. https://doi.org/10.2307/3650139

Muhammad, N., Waren, L., \& Binte-Saleem, S. (2017). Anything can happen, anytime: the impact of conflict on women's entrepreneurship in Pakistan. Journal of Developmental Entrepreneurship, 22(4), 1750025-11750025-23. https://doi.org/10.1142/S108494671750025X

OECD. (n.d.) Business demography indicators ISIC Rev. 4.

OECD. (2013). Entrepreneurship at a Glance 2013. OECD Publishing.

Platzek, B. P., Pretorius, L., \& Winzker, D. H. (2014). The vital entrepreneurial learning organization: a corporate mindset for entrepreneurial change management. International Journal of Innovation and Technology Management, 11(06), 1450044-1-1450044-14. https://doi.org/10.1142/S0219877014500448 
Porter, M. E. (1985). Technology and competitive advantage. Journal of Business Strategy, 5(3), 60-78. https://doi.org/10.1108/eb039075

Pretorius, L., \& Pretorius, J. H. C. (2014). Technology interaction during cyclic conditions. The 8th International Scientific Conference of Business and Management 2014 (pp. 666-672).

https://doi.org/10.3846/bm.2014.081

Roman, A., Bilan, I., \& Ciumaș, C. (2018). What drives the creation of new businesses? A panel-data analysis for EU countries. Emerging Markets Finance and Trade, 54(3), 508-536. https://doi.org/10.1080/1540496X.2017.1412304

Saeed, K. (2014). Policy space and system dynamics modeling of environmental agendas. Retrieved from http://digitalcommons.wpi.edu/ssps-papers/4/
Sterman, J. D. (2000). Business dynamics. McGraw-Hill, Inc. Teixeira, S. J., Casteleiro, C. M. L., Rodrigues, R. G., \& Guerra, M. D. (2018). Entrepreneurial intentions and entrepreneurship in European countries. International Journal of Innovation Science, 10(1), 22-42. https://doi.org/10.1108/IJIS-07-2017-0062

Tvaronavičienè, M. (2016). Start-ups across the EU: if particular tendencies could be traced. Entrepreneurship and Sustainability Issues, 3(3), 290-298. https://doi.org/10.9770/jesi.2016.3.3(6)

Van der Lingen, E., \& van Niekerk, G. (2015). Entrepreneurship traits of science, engineering and technology (SET) students. The Southern African Journal of Entrepreneurship and Small Business Management, 7(1), 117-144. https://doi.org/10.4102/sajesbm.v7i1.1 